\title{
Session 4pAOa
}

\section{Acoustical Oceanography, Underwater Acoustics, and ECUA: Rapid Environmental Assessment}

\author{
John C. Osler, Cochair \\ Defence R\&D Canada - Atlantic, P.O. Box 1012, Dartmouth, NS B2Y3Z7, Canada \\ Yann Stephan, Cochair \\ SHOM, 13 rue du Chatellier, CS 92803, Brest cedex 2, 29228, France
}

Invited Paper

2:00

\begin{abstract}
4pAOa1. Overview of U.S. Navy Operational Oceanographic Models in Support of Aconstic Applications. Richard Allard (Naval Research Laboratory, NRL Code 7322, Stennis Space Center, MS 39571, USA, allard@nrlssc.navy.mil), Charlie Barron (Naval Research Laboratory, NRL Coded 7323, Stennis Space Center, MS 39529, USA, barron@ nrlssc.navy.mil), Frank Bub (Naval Oceanographic Office, Balch Blvd, Stennis Space Center, MS 39529, USA, frank.bub@navy.mil), Emanuel F. Coelho (University of Southern Mississippi. Balch Blvd, Stennis Space Center, MS 39529, USA, coelho@nrlssc.navy.mil), James Cummings (Naval Research Laboratory, NRL Code 7322, Stennis Space Center, MS 39571. USA, cummings@ nrlmry.navy.mil), J. Pacquin Fabre (Naval Research Laboratory, NRL Code 7322, Stennis Space Center, MS 39571, USA, josie.fabre@nrlssc.navy.mil), Robert Helber (Naval Research Laboratory, NRL Code 7322, Stennis Space Center, MS 39571, USA, helber@nrlssc.navy.mil), Clark Rowley (Naval Research Laboratory, NRL Code 7322, Stennis Space Center, MS 39571, USA, rowley@nrlssc.navy.mil)
\end{abstract}

The Naval Oceanographic Office operational global $1 / 8^{\circ}$ Navy Coastal Ocean Model assimilates satellite and in-situ data to produce daily 72-hr forecasts. Output includes 3D fields of temperature, salinity, u- and v-components of ocean currents at standard depth levels, and these support derived fields including sound speed and sonic layer depth. The global model provides initial/boundary conditions for nested regional models, primarily relocatable NCOM. The relocatable NCOM modeling system can be set up quickly for areas of interest, includes river and tidal forcing, and is forced with a high-resolution atmospheric mesoscale model. Local and remote observations are incorporated into the models through the Navy Coupled Ocean Data Assimilation system, which assimilates sea surface temperature data from satellite, ships and buoys, profile data from floats and gliders, xbt's, CTD's, fixed and drifting buoys as well as altimeter-derived sea surface heights and ice concentration. In this presentation we will discuss how the operational ocean models feed into acoustic prediction models and tactical decision aids, the role glider observations will play in the modeling strategy, the use of ensembles to provide improved prediction error estimates and guide new observations, and future plans.

\section{Contributed Paper}

$2: 20$

4pAOa2. High-frequency multibeam echosounder classification for rapid environmental assessment. Kerstin Siemes (Acoustic Remote Sensing Group, Delft Institute of Earth Observation and Space Systems, Delft University of Technology, Kluyverweg 1,2629 HS Delft, Netherlands, k.siemes@tudelft.nl), Mirjam Snellen (Acoustic Remote Sensing Group, Delft Institute of Earth Observation and Space Systems, Delft University of Technology, Kluyverweg 1, 2629 HS Delft, Netherlands, m.snellen @tudelft.nl), Dick G. Simons (Delft University of Technology, P.O. Box Postbus 5048, 2600 GA Delft, Netherlands, d.g.simons@tudelft .nl), Jean-Pierre Hermand (Université libre de Bruxelles (U.L.B.) - Environmental hydroacoustics lab, av. Franklin D. Roosevelt 50, CP 194/5, 1050 Bruxelles, Belgium, jhermand@ulb.ac.be), Matthias Meyer (Royal Netherlands Naval College (NLDA) - REA group, PO Box 10000, 1780 Den Helder, Netherlands, mmeyer@ulb.ac.be), Jean-Claude Le Gac (NATO Undersea Research Center, Viale San Bartolomeo 400, 19126 La Spezia, Italy, legac@nurc.nato.int)

For shallow-water naval operations, obtaining rapidly an accurate picture of the environmental circumstances often is of high importance. Hereto a multi-sensor approach is required. In this context, the MREA/BP'07 ex- periment has been carried out south of Elba (Mediterranean Sea), where several techniques of environmental characterization covering the fields of underwater acoustics, physical oceanography and geophysics have been combined [Le Gac\&Hermand, 2007]. The required information typically concerns water-column properties, sea surface roughness, and sediment geoacoustic properties. Estimating these geo-acoustic parameters from inversion of acoustic data received on drifting sparse arrays has proved to be a promising approach. Part of MREA/BP'07 was therefore dedicated to this type of measurement. For validating the resulting geo-acoustic estimates sediment samples were collected. Additionally, measurements were carried out using a multibeam-echosounder. This system provides depth information, but also allows for seafloor classification. The classification approach taken is model-based employing the backscatter data. It discriminates between sediments in the most optimal way by applying the Bayes decision rule for multiple hypotheses, implicitly accounting for backscatter-strength ping-to-ping variability. Here, results of seafloor classification using the multibeam data and a preliminary comparison with the sediment sample analysis and the geo-acoustic parameter estimates as obtained from the drifting arrays are presented. 